Article

\title{
First-Principles Exploration of Hazardous Gas Molecule Adsorption on Pure and Modified $\mathrm{Al}_{60} \mathrm{~N}_{60}$ Nanoclusters
}

\author{
Qi Liang ${ }^{1}, X_{i}$ Nie $^{1}$, Wenzheng Du ${ }^{1}$, Pengju Zhang ${ }^{1}$, Lin Wan ${ }^{1}{ }^{\circledR}$, Rajeev Ahuja ${ }^{2,3}{ }^{\circledR}$, Jing Ping ${ }^{4}$ \\ and Zhao Qian ${ }^{1, *}$ \\ 1 Key Laboratory of Liquid-Solid Structural Evolution and Processing of Materials (Ministry of Education) \& \\ School of Software, Shandong University, Jinan 250061, China; 18536228352@139.com (Q.L.); \\ 17861412028@139.com (X.N.); 201813740@mail.sdu.edu.cn (W.D.); zpj201813800@mail.sdu.edu.cn (P.Z.); \\ wanlin@sdu.edu.cn (L.W.) \\ 2 Condensed Matter Theory, Department of Physics and Astronomy, Ångström Laboratory, \\ Uppsala University, 75120 Uppsala, Sweden; rajeev.ahuja@physics.uu.se \\ 3 Applied Materials Physics, Department of Materials Science and Engineering, KTH Royal Institute of \\ Technology, 10044 Stockholm, Sweden \\ 4 College of Traditional Chinese Medicine, Shandong University of Traditional Chinese Medicine, \\ Jinan 250355, China; pingjing@sdutcm.edu.cn \\ * Correspondence: qianzhao@sdu.edu.cn
}

Received: 17 September 2020; Accepted: 4 October 2020; Published: 29 October 2020

\begin{abstract}
In this work, we use the first-principles method to study in details the characteristics of the adsorption of hazardous $\mathrm{NO}_{2}, \mathrm{NO}, \mathrm{CO}_{2}, \mathrm{CO}$ and $\mathrm{SO}_{2}$ gas molecules by pure and heteroatom (Ti, $\mathrm{Si}, \mathrm{Mn}$ ) modified $\mathrm{Al}_{60} \mathrm{~N}_{60}$ nanoclusters. It is found that the pure $\mathrm{Al}_{60} \mathrm{~N}_{60}$ cluster is not sensitive to CO. When $\mathrm{NO}_{2}, \mathrm{NO}, \mathrm{CO}_{2}, \mathrm{CO}$ and $\mathrm{SO}_{2}$ are adsorbed on $\mathrm{Al}_{60} \mathrm{~N}_{60}$ cluster'stop.b, edge. $\mathrm{a}_{\mathrm{p}}$, edge. $\mathrm{a}_{\mathrm{h}}$, edge. $a_{p}$ andedge. $a_{h}$ sites respectively, the obtained configuration is the most stable for each gas. $\mathrm{Ti}, \mathrm{Si}$ and $\mathrm{Mn}$ atoms prefer to stay on the top sites of $\mathrm{Al}_{60} \mathrm{~N}_{60}$ cluster when these heteroatoms are used to modify the pure clusters. The adsorption characteristics of above hazardous gas molecules on these hetero-atom modified nanoclusters are also revealed. It is found that when Ti- $\mathrm{Al}_{60} \mathrm{~N}_{60}$ cluster adsorbs $\mathrm{CO}$ and $\mathrm{SO}_{2}$, the energy gap decreases sharply and the change rate of gap is $62 \%$ and $50 \%$, respectively. The Ti-modified $\mathrm{Al}_{60} \mathrm{~N}_{60}$ improves the adsorption sensitivity of the cluster to $\mathrm{CO}$ and $\mathrm{SO}_{2}$. This theoretical work is proposed to predict and understand the basic adsorption characteristics of AlN-based nanoclusters for hazardous gases, which will help and guide researchers to design better nanomaterials for gas adsorption or detection.
\end{abstract}

Keywords: environment and health; first-principles physics; DFT; electronic structure; hazardous gas

\section{Introduction}

In recent years, industrial and fossil-fuel motor exhaust gases and the flue gas from the burning of garbage and straw crops in some areas have come to harm humans and the environment. These gases accumulate in the air and undergo a series of complex chemical reactions with the dust, small particles, bacteria, etc. in the air to form small agglomerated particles. When their concentration reaches a certain level and is further affected by weather, smog could appear. These hazardous gases include nitrogen dioxide $\left(\mathrm{NO}_{2}\right)$, carbon monoxide $(\mathrm{CO})$, nitric oxide $(\mathrm{NO})$, carbon dioxide $\left(\mathrm{CO}_{2}\right)$ and sulfur dioxide $\left(\mathrm{SO}_{2}\right)$, etc. Some of these gases are irritating and toxic gases which are the main source of acid rain. Some have strong oxidizing properties and are strong combustion aids and some gases can cause greenhouse effects. They harm people's health and pollute the environment, thus the adsorption 
and detection of these gases are of great significance to environmental protection and human health. From the perspective of materials, it is very important to find material substrates with high sensitivity to these gases. At present, nanoclusters, nanosheets, nanotubes and other low-dimensional nanomaterials are regarded to be potential candidates for these applications [1-3].

$\mathrm{AlN}$ is a kind of semiconducting material with excellent physical and chemical properties and its unique nanostructures have attracted the attentions of gas sensing researchers [4-11]. The electronic properties of nanomaterials can be improved by atomic modification or doping [12-15]. For example, Rezaei-Sameti et al. studied the adsorption characteristics of pure, B-, As-doped AlN nanotubes for $\mathrm{CO}$ adsorption [16]. The results showed that doping with $\mathrm{B}$ and As atoms was conducive to $\mathrm{CO}$ gas adsorption and effectively improved the sensitivity of AlN nanotubes to CO gas. Saedi et al. [17] considered the adsorption of $\mathrm{H}_{2} \mathrm{~S}, \mathrm{COS}, \mathrm{CS}_{2}$ and $\mathrm{SO}_{2}$ gases by $\mathrm{Al}_{12} \mathrm{~N}_{12}$ nanoclusters using density functional theory and it had been revealed that the $\mathrm{Al}_{12} \mathrm{~N}_{12}$ nanocluster was a promising $\mathrm{SO}_{2}$ gas and electronic sensor and a $\mathrm{CS}_{2}$ gas electronic sensor, while they had different effects on conductivity. The theoretical investigations of AlN-based low-dimensional nanomaterials in this field are not only interesting to unveil some physics in the area but also of significance to move forward the field.

Based on previous research on AlN nanoclusters [18], in this work we have investigated the adsorption behaviors of $\mathrm{NO}_{2}, \mathrm{NO}, \mathrm{CO}_{2}, \mathrm{CO}$, and $\mathrm{SO}_{2}$ molecules on the large $\mathrm{Al}_{60} \mathrm{~N}_{60}$ cluster. We select more stable adsorption sites to study their adsorption characteristics and electronic structures. Beside the pure cluster, some heteroatoms such as $\mathrm{Ti}$, $\mathrm{Si}$ and $\mathrm{Mn}$ are also used to modify the $\mathrm{Al}_{60} \mathrm{~N}_{60}$ nanocluster as substrates, for each of which the most stable sites are respectively considered to adsorb the above five gases and the sensitivity of each modified cluster to the gas molecules are also studied systematically.

\section{Theoretical Methods}

In this work, the first-principles method based on Density Functional Theory (DFT) [19,20] is used. The Vienna ab-initio simulation package [21-23] is employed to optimize the geometry structures and calculate the energetics and electronic structures of various gas adsorption on pure and hetero-atom modified nanoclusters. The projector augmented wave (PAW) [21] pseudopotentials are used to describe the ion-electron interactions. The exchange correlation potentials are treated by the Perdew-Burke-Ernzerhof (PBE) functional within the framework of the generalized gradient approximation [24]. Due to the van der Waals interaction between the atomic cluster and the gas molecule, we have used DFT-D2 method of Grimme [25] to make the correction. The plan wave basis set with an energy cut-off of $520 \mathrm{eV}$ has been used. The Brillouin zone is sampled using the Monkhorst-Pack method and the supercell approach is used for structural optimizations and electronic structure calculations. The conjugate gradient algorithm is used to optimize the geometry structures and the convergence criterion of the atomic force is less than $0.02 \mathrm{eV} / \AA$. The charge transfer between $\mathrm{Al}_{60} \mathrm{~N}_{60}$ nanocluster and hazardous gas molecules were analyzed by the Bader charge analysis using the previous method [26-28]. In order to avoid interaction between clusters in $x, y$ and $z$ directions, all the models are separated by the vacuum space of $20 \AA$. The following formula is utilized to calculate the adsorption energies:

$$
E_{\mathrm{ad}}=\mathrm{E}_{\text {cluster+gas }}-\mathrm{E}_{\text {cluster }}-\mathrm{E}_{\text {gas }}
$$

where $\mathrm{E}_{\mathrm{cluster+gas}}$ represents the total energy of the cluster (pure or hetero-atom modified) after gas molecule adsorption, $E_{\text {cluster }}$ and $E_{\text {gas }}$ represent the energies of the bare cluster and gas molecule respectively.

\section{Results and Discussion}

\subsection{Adsorption of $\mathrm{NO}_{2}, \mathrm{NO}, \mathrm{CO}_{2}, \mathrm{CO}$ and $\mathrm{SO}_{2}$ by Pure $\mathrm{Al}_{60} \mathrm{~N}_{60}$ Nanocluster}

Firstly, we have systematically considered the adsorption of $\mathrm{NO}_{2}, \mathrm{NO}, \mathrm{CO}_{2}, \mathrm{CO}$ and $\mathrm{SO}_{2}$ on the surface of pure $\mathrm{Al}_{60} \mathrm{~N}_{60}$ nanoclusters, the structure of which had been revealed by us in an earlier study. There are different adsorption positions (we designate them as the edge, side and top position in this 
work) on the surface of clusters, and these three positions have four, two and two different adsorption sites, respectively. In Figure 1, Figure 1a shows the four adsorption sites at the edge position: edge.a (N-site) and edge.b (Al-site) have four coordination, edge.c (N-site) and edge.d (Al-site) have three coordination. Figure $1 \mathrm{~b}$ shows the adsorption sites of the side position: side.a and side.b are the sites at the concave $\mathrm{N}$ atom and the Al-N bond, respectively. Figure 1c illustrates the two sites at the top position: top.a and top.b are the sites at the center and the Al-N bond, respectively. The $\mathrm{NO}_{2}, \mathrm{NO}_{2} \mathrm{CO}_{2}$, $\mathrm{CO}$ and $\mathrm{SO}_{2}$ molecules are horizontally or vertically placed in front of the edge and side sites and are horizontally placed directly above the top two sites for adsorption. Here, the readers may ask why we don't adopt the cluster model with passivated heteroatoms or functional group such as $\mathrm{H}, \mathrm{O}, \mathrm{OH}$, etc. in this study, since the cluster may react in air or solution. There are mainly two reasons: one is that the real cluster structure after passivation in air or solution would be very complicated, i.e., it is hard to define what kinds of heteroatoms or functional group $(\mathrm{H}, \mathrm{O}, \mathrm{OH}$, etc.) passivate which specific sites of the cluster. It may be argued that this can be run through in every possible "combination", but the computational time and cost would be huge considering that only for one model there will be 14 different adsorption configurations for each kind of gas molecule (more details will be in the following paragraph) and we have five different gas molecules to investigate in total. The other is that in our intrinsic cluster model, most surface $\mathrm{Al} / \mathrm{N}$ atoms have three or four coordinations and the $\mathrm{Al}-\mathrm{N}$ bonds are almost saturated, similar case also exists in other research [17]. Thus in this fundamental study we employ the current model to explore the intrinsic adsorption properties of $\mathrm{Al}_{60} \mathrm{~N}_{60}$ nanocluster.
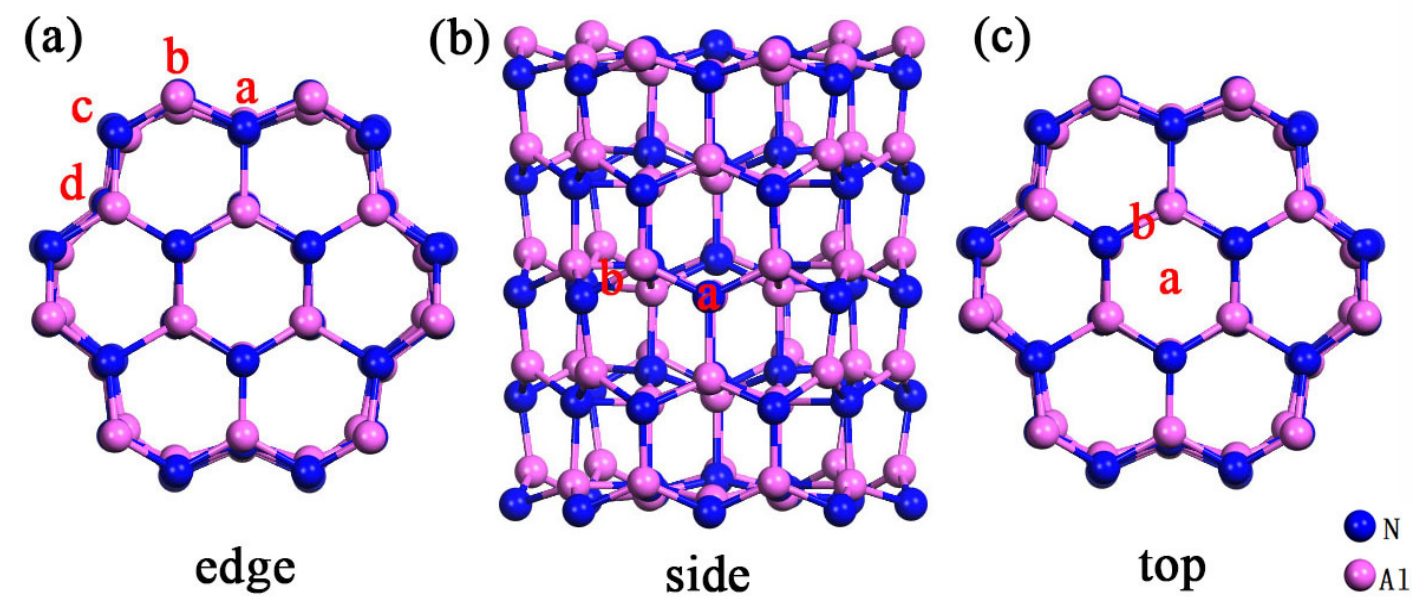

Figure 1. Various adsorption sites (shown in red letters) at each position (a) edge, (b) side or (c) top of pure $\mathrm{Al}_{60} \mathrm{~N}_{60}$ cluster.

Based on the above model, there are 14 different adsorption configurations for each kind of gas molecule. We have systematically studied the adsorption characteristics of each gas at various sites, as shown in Table 1 . The subscripts $h$ and $p$ represent the horizontal and perpendicular adsorption of gas molecules at each site. From the data of adsorption energy, it can be seen that compared with other four gases, the adsorption energy absolute values of pure $\mathrm{Al}_{60} \mathrm{~N}_{60}$ cluster towards $\mathrm{CO}$ are generally smaller. The adsorption energies of $\mathrm{NO}_{2}, \mathrm{NO}, \mathrm{CO}_{2}$ and $\mathrm{CO}$ are relatively high at edge.a site. In addition, it is also found that when these five gas molecules are adsorbed at the top position, the adsorption energy value obtained at the Al-N bond site is high. When $\mathrm{NO}_{2}$ and $\mathrm{CO}_{2}$ are adsorbed at the side sites and $\mathrm{SO}_{2}$ is adsorbed at the edge. $\mathrm{c}_{\mathrm{h}}$ and side. $\mathrm{a}_{\mathrm{p}}$ sites, the adsorption energy values are more than $10 \mathrm{eV}$. Therefore, we have studied the adsorption details of these five gases at these sites. The optimized configurations corresponding to the higher energy values are shown in Figure 2. It can be seen from the Figure 2 that when the adsorption energy values are large, the corresponding optimized configurations have obvious shrinkage deformation such as $\mathrm{NO}_{2}$ adsorption at the side. $\mathrm{a}_{\mathrm{h}}$ and side. $b_{\mathrm{h}}$ sites, $\mathrm{CO}_{2}$ adsorption at the side. $\mathrm{a}_{\mathrm{p}}$ and side. $\mathrm{b}_{\mathrm{h}}$ sites, and $\mathrm{SO}_{2}$ adsorption at the edge. $\mathrm{c}_{\mathrm{h}}$ 
and side.a $a_{\mathrm{p}}$. When $\mathrm{NO}_{2}$ is adsorbed at the edge. $\mathrm{a}_{\mathrm{h}}$ site, the structure of the edge position is obviously deformed. From the optimized model structure, it can be seen that when the gas molecules are located at the edge and side sites, the structure is prone to deform.

Table 1. The adsorption energies of various gas molecules adsorbed on different sites of pure $\mathrm{Al}_{60} \mathrm{~N}_{60}$ nanocluster.

\begin{tabular}{|c|c|c|c|c|c|c|c|c|c|c|c|c|c|c|}
\hline \multicolumn{15}{|c|}{ Sites } \\
\hline \multirow{2}{*}{$\begin{array}{l}E_{a d} \\
(e V)\end{array}$} & \multicolumn{8}{|c|}{ Edge } & \multicolumn{4}{|c|}{ Side } & \multicolumn{2}{|c|}{ Top } \\
\hline & $a_{h}$ & $a_{p}$ & $\mathbf{b}_{\mathrm{h}}$ & $b_{p}$ & $c_{h}$ & $c_{p}$ & $d_{h}$ & $d_{p}$ & $a_{h}$ & $a_{p}$ & $\mathbf{b}_{\mathrm{h}}$ & $b_{p}$ & a & b \\
\hline $\mathrm{E}_{\mathrm{ad}+\mathrm{NO}_{2}}$ & -4.77 & -4.41 & -4.41 & -3.39 & -2.98 & -2.88 & -4.22 & -3.17 & -18.21 & -0.22 & -10.77 & -2.79 & -0.31 & -3.32 \\
\hline $\mathrm{E}_{\mathrm{ad}+\mathrm{NO}}$ & -2.02 & -2.60 & -2.01 & -1.99 & -2.01 & -1.97 & -1.58 & -0.17 & -0.81 & -1.38 & -0.83 & -0.83 & -0.36 & -0.38 \\
\hline $\mathrm{E}_{\mathrm{ad}+\mathrm{CO}_{2}}$ & -2.36 & -0.12 & -0.11 & -0.09 & -0.17 & -0.28 & -0.90 & -0.37 & -0.35 & -10.04 & -10.04 & -0.25 & -0.29 & -0.30 \\
\hline $\mathrm{E}_{\mathrm{ad}+\mathrm{CO}}$ & -0.99 & -1.47 & -0.97 & -0.97 & -0.09 & -0.75 & -0.08 & -0.26 & -0.74 & -0.16 & -0.75 & -0.12 & -0.13 & -0.23 \\
\hline $\mathrm{E}_{\mathrm{ad}+\mathrm{SO}_{2}}$ & -4.49 & -3.95 & -2.36 & -1.00 & -13.90 & -1.78 & -2.18 & -1.79 & -3.76 & -10.82 & -1.61 & -3.23 & -0.44 & -3.43 \\
\hline
\end{tabular}

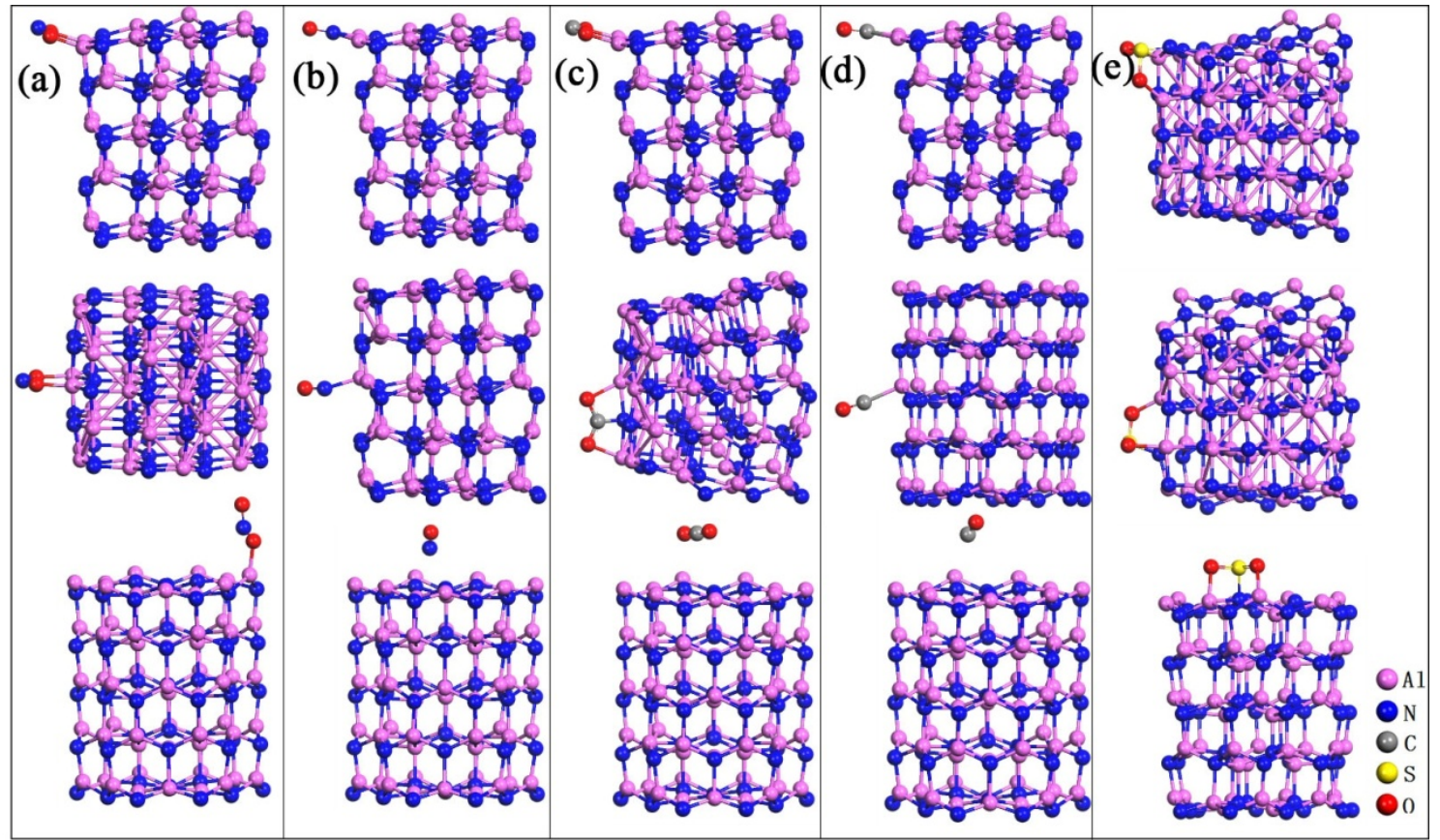

Figure 2. The configurations of pure $\mathrm{Al}_{60} \mathrm{~N}_{60}$ clusters adsorbing hazardous gas molecules at three positions with higher adsorption energy values: (a) $\mathrm{NO}_{2}$, (b) $\mathrm{NO}$, (c) $\mathrm{CO}_{2}$, (d) $\mathrm{CO}$, (e) $\mathrm{SO}_{2}$. Top down in each subbox: the edge, side and top adsorption positions of clusters respectively.

In order to further study the electronic structures of the pure $\mathrm{Al}_{60} \mathrm{~N}_{60}$ cluster adsorbing these five gases, we have selected the relatively stable structures when the $\mathrm{Al}_{60} \mathrm{~N}_{60}$ cluster adsorbs those gas molecules. After screening, five configurations were obtained: $\mathrm{NO}_{2}, \mathrm{NO}, \mathrm{CO}_{2}, \mathrm{CO}$ and $\mathrm{SO}_{2}$ adsorbed at the cluster top.b, edge. $a_{p}$, edge. $a_{h}$, edge. $a_{p}$ and edge. $a_{h}$ sites, respectively. Compared with other sites of the same gas, these structures are more stable and the adsorption energy values are higher. Based on this, the electronic properties are further studied.

In Figure 3, the differential charge density and charge transfer of the five gas molecules adsorbed at the relatively stable sites are illustrated. The $\mathrm{O}$ atoms of $\mathrm{NO}_{2}, \mathrm{CO}_{2}$ and $\mathrm{SO}_{2}$ are bonded with the $\mathrm{Al}$ atom at the edge of cluster, and the charge density of $\mathrm{O}$ atom after bonding is spindle-shaped. When the pure $\mathrm{Al}_{60} \mathrm{~N}_{60}$ cluster adsorbs $\mathrm{NO}_{2}, \mathrm{NO}, \mathrm{CO}_{2}, \mathrm{CO}$ and $\mathrm{SO}_{2}$, charge is transferred from the nanocluster to the gas molecules. The charge transfer of these five systems is not small. We also calculated the electronic structures of these five systems, as shown in Figure 4. After the pure $\mathrm{Al}_{60} \mathrm{~N}_{60}$ cluster adsorbs $\mathrm{NO}_{2}$, the electronic structure changes significantly. From the density of states curve, 
it can be seen that after the adsorption of $\mathrm{NO}_{2}$, a new energy level appears between the Fermi level and the conduction band bottom. Before adsorption, the energy gap of pure $\mathrm{Al}_{60} \mathrm{~N}_{60}$ cluster is $1.297 \mathrm{eV}$. After adsorption, the energy gap of the system becomes $0.721 \mathrm{eV}$ and the change rate of gap is $44.40 \%$. The pure $\mathrm{Al}_{60} \mathrm{~N}_{60}$ cluster is relatively sensitive to $\mathrm{NO}_{2}$. When the pure $\mathrm{Al}_{60} \mathrm{~N}_{60}$ cluster adsorbs $\mathrm{CO}_{2}$, $\mathrm{NO}$ and $\mathrm{SO}_{2}$, the energy gap change by $0.035 \mathrm{eV}, 0.08 \mathrm{eV}$ and $0.035 \mathrm{eV}$, respectively. Before and after the adsorption of $\mathrm{CO}$ by pure $\mathrm{Al}_{60} \mathrm{~N}_{60}$, the energy gap changes by $0.945 \mathrm{eV}$ and the change rate is $27.14 \%$.
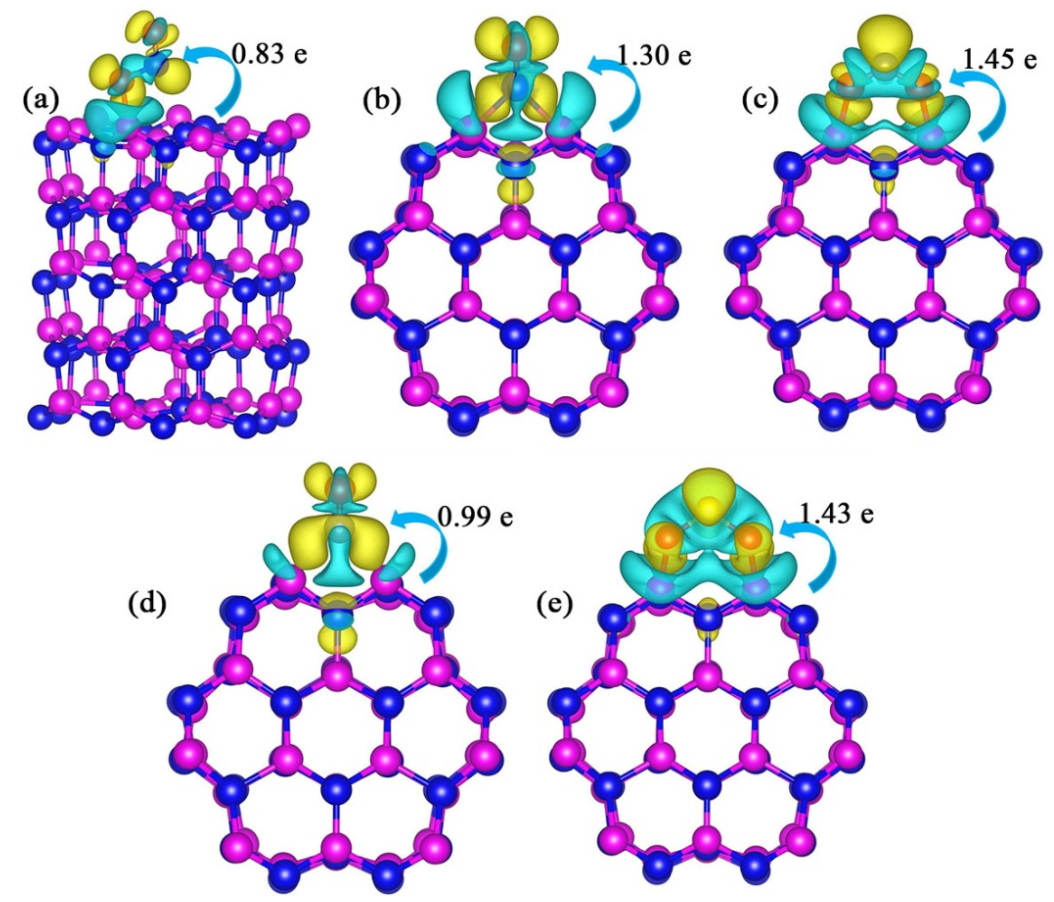

Figure 3. Differential charge density and charge transfer of (a) $\mathrm{NO}_{2}$ adsorbed at top.b site, (b) $\mathrm{NO}$ adsorbed at edge.ap site, (c) $\mathrm{CO}_{2}$ adsorbed at edge. $\mathrm{a}_{\mathrm{h}}$ site, (d) $\mathrm{CO}$ adsorbed at edge.ap site and (e) $\mathrm{SO}_{2}$ adsorbed at edge. $a_{\mathrm{h}}$ site. Yellow and blue represent the charge accumulation and depletion respectively. The isosurface value is $0.0025 \mathrm{e} / \AA^{3}$. The arrow and charge number in the figure indicate the direction and value of the charge transfer between the nanocluster and the gas molecule.

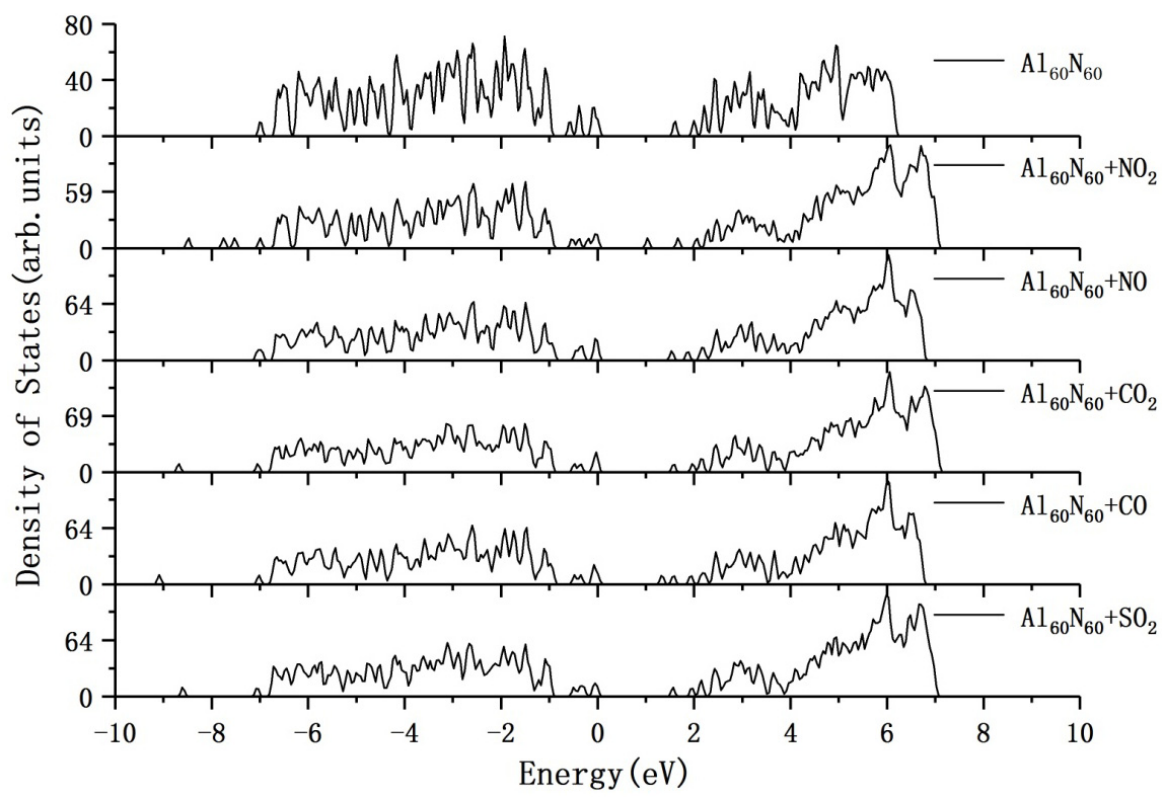

Figure 4. The electronic density of states of pure $\mathrm{Al}_{60} \mathrm{~N}_{60}$ cluster before and after adsorption of various gas molecules. The Fermi level is set at zero. 


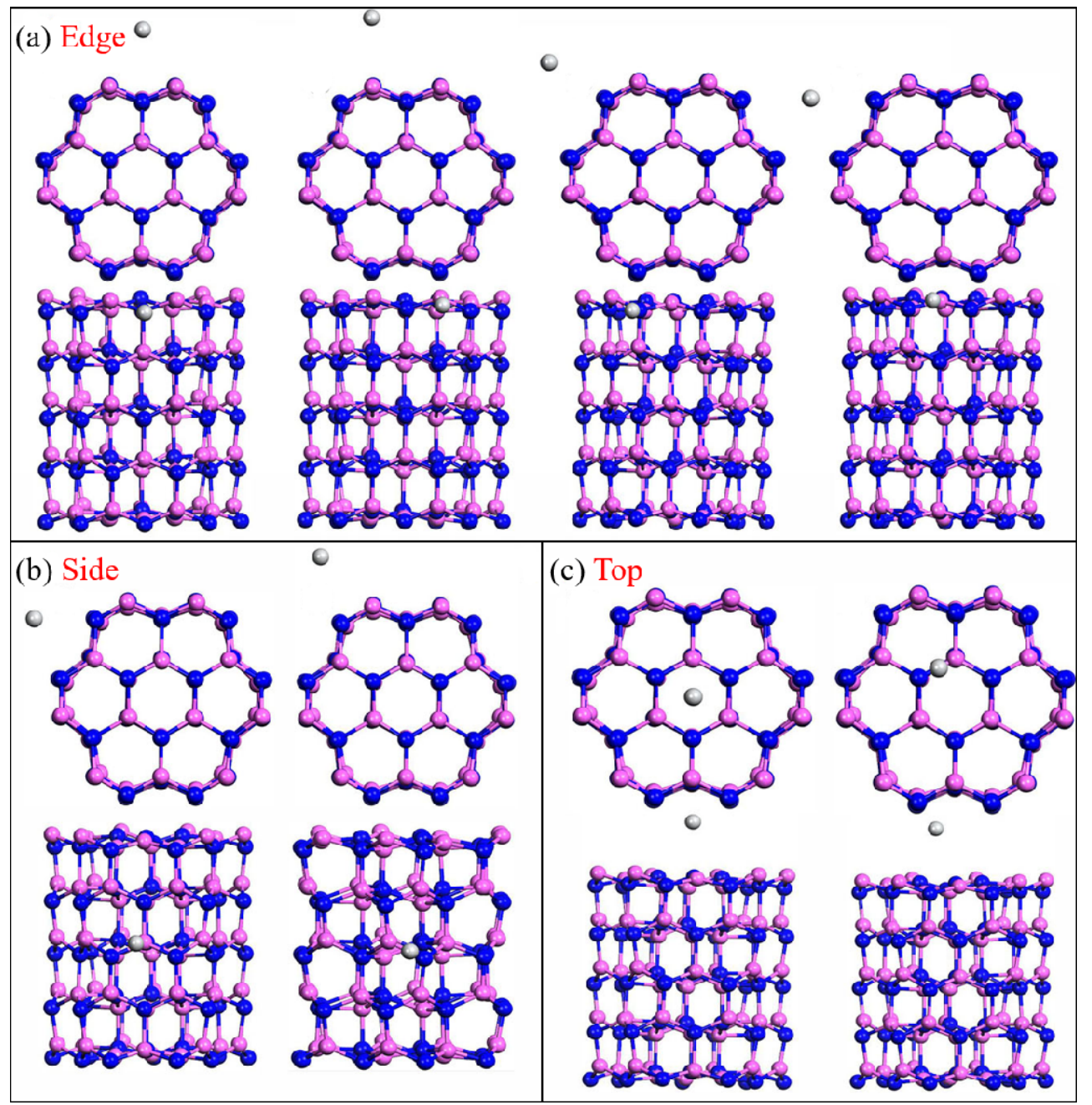

Figure 5. Top view and side view of the edge, side and top positions of $\mathrm{Al}_{60} \mathrm{~N}_{60}$ cluster adsorbing single $\mathrm{M}$ atom ( $\mathrm{M}$ atom is Ti, $\mathrm{Si}$ and $\mathrm{Mn}$ respectively): (a) Edge: From left to right, the $\mathrm{M}$ atom is located in front of the four-coordinated $\mathrm{N}$ atom, two-coordinated $\mathrm{Al}$ atom, three-coordinated $\mathrm{N}$ atom and three-coordinated $\mathrm{Al}$ atom at the edge position, respectively. (b) Side: From left to right, $\mathrm{M}$ atom is located in front of the $\mathrm{Al}$ atom recessed and $\mathrm{Al}-\mathrm{N}$ bond at the side position, respectively. (c) Top: From left to right, $\mathrm{M}$ atom is located above the center of the top six-member ring and the top Al-N bond, respectively. The pink, blue and silver-white spheres represent $\mathrm{Al}, \mathrm{N}$, and $\mathrm{M}$ atoms, respectively.

\subsection{Atomic Modification of $A l_{60} N_{60}$ Cluster by Ti, Si and $M n$}

In order to further improve the adsorption and sensitivity of the cluster to those five gases, in this work we have tried to modify the $\mathrm{Al}_{60} \mathrm{~N}_{60}$ cluster with $\mathrm{Ti}$, Si and $\mathrm{Mn}$ heteroatoms and systematically calculated the adsorption energy, adsorption distance, bond length, bond angle and electronic structure of each system. Since the surface of the $\mathrm{Al}_{60} \mathrm{~N}_{60}$ cluster has many different sites, first of all, we have to determine at which site each heteroatom is prone to occupy and which structure is relatively stable. These two aspects are discussed in the following research. When Ti, Si or Mn heteroatoms are adsorbed at the edge, side and top positions of $\mathrm{Al}_{60} \mathrm{~N}_{60}$ cluster surface, there are four, two, and two adsorption sites, respectively, as shown in Figure 5. We have studied these eight adsorption structures and calculated the adsorption energy of each structure as shown in Table 2. It is found that when a Ti, $\mathrm{Si}$ or $\mathrm{Mn}$ atom is adsorbed at the side.a site the respective adsorption energies are $-14.17 \mathrm{eV},-12.35 \mathrm{eV}$ and $-11.38 \mathrm{eV}$, which shows that the adsorption energy values of these three adsorption systems are generally higher. When these heteroatoms are adsorbed at some sites of the cluster, the adsorption energy is about $10 \mathrm{eV}$ higher than other sites. To know the reason why the adsorption energy changes 
so much, we have studied the structures after adsorption and selected the geometrically optimized configurations with stable adsorption of the three hetero-atoms at the edge, side and top positions of the cluster as shown in Figure 6. When the cluster adsorbs Ti, Si or Mn atom at the side position, the structures shrink greatly. After the cluster edge.d site adsorbs a Ti atom, the structure also deforms obviously. The system with obvious deformation of structure after optimization has a relatively high adsorption energy value and unstable structure. Next, we will further study them from the aspect of electronic structures.

Table 2. Adsorption energies of Ti, Si or Mn hetero-atom at different sites of $\mathrm{Al}_{60} \mathrm{~N}_{60}$ cluster.

\begin{tabular}{cccccccccc}
\hline & \multicolumn{10}{c}{ Sites } & \multicolumn{1}{c}{ Side } & \multicolumn{3}{c}{ Top } \\
\hline \multirow{2}{*}{$\mathbf{E}_{\mathbf{a d}}(\mathbf{e V})$} & $\mathbf{a}$ & $\mathbf{b}$ & $\mathbf{c}$ & $\mathbf{d}$ & $\mathbf{a}$ & $\mathbf{b}$ & $\mathbf{a}$ & $\mathbf{b}$ \\
\hline $\mathrm{E}_{\mathrm{ad}+\mathrm{Ti}}$ & -3.21 & -3.20 & -3.36 & -14.67 & -14.17 & -5.53 & -4.80 & -4.82 \\
$\mathrm{E}_{\mathrm{ad}+\mathrm{Si}}$ & -3.64 & -3.63 & -2.55 & -2.82 & -12.35 & -6.63 & -4.33 & -3.40 \\
$\mathrm{E}_{\mathrm{ad}+\mathrm{Mn}}$ & -2.58 & -2.59 & -1.61 & -1.94 & -11.38 & -3.02 & -2.95 & -2.67 \\
\hline
\end{tabular}
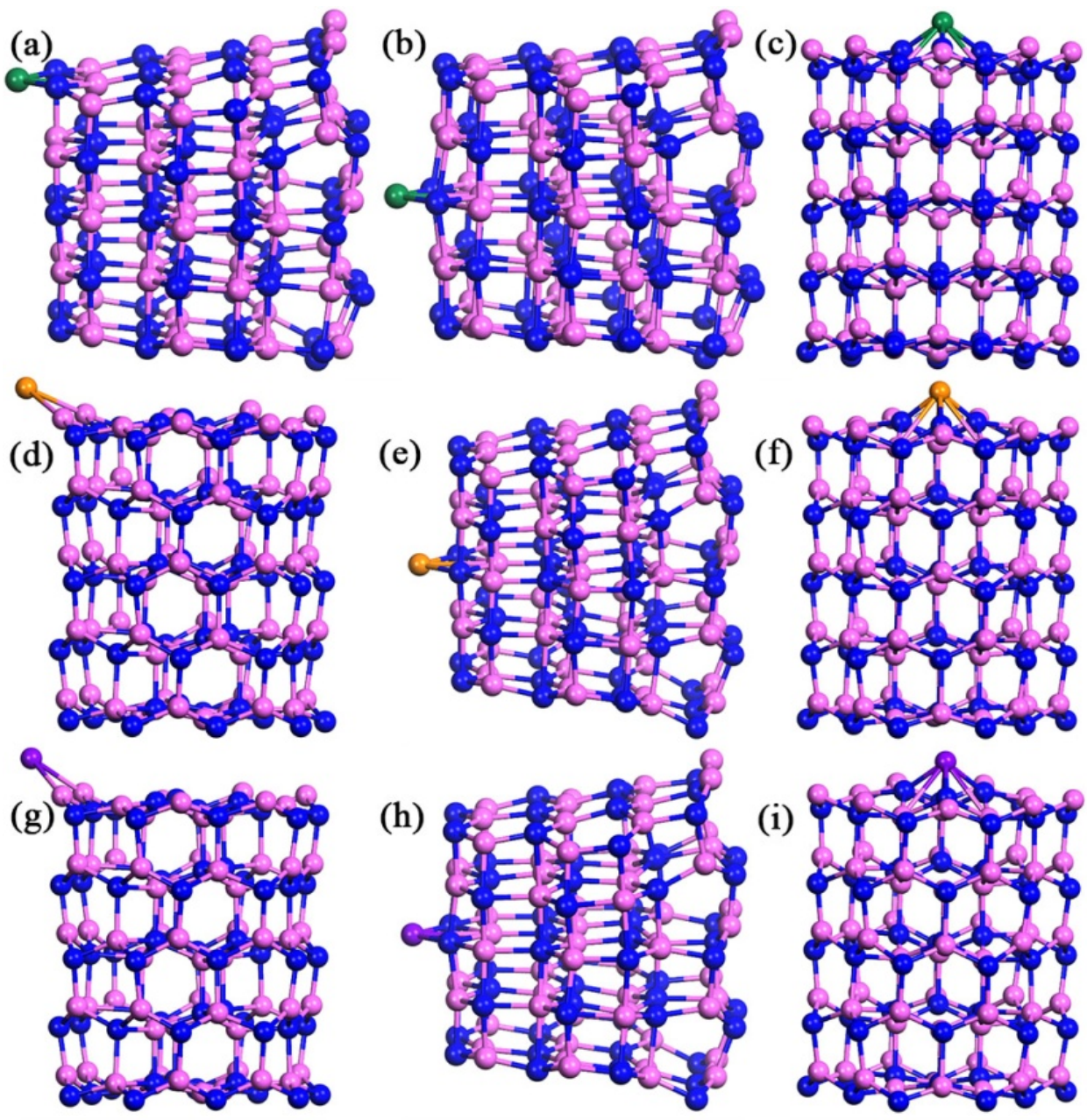

(e)

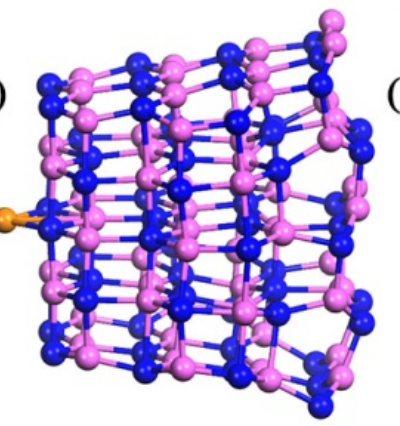

(h)

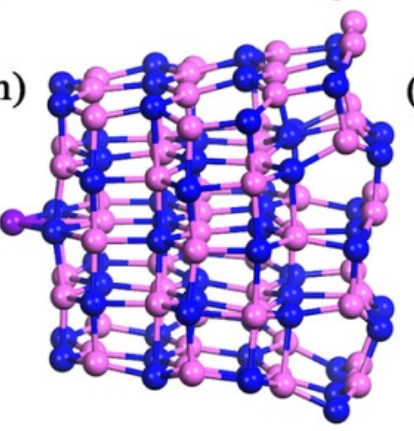

(f)

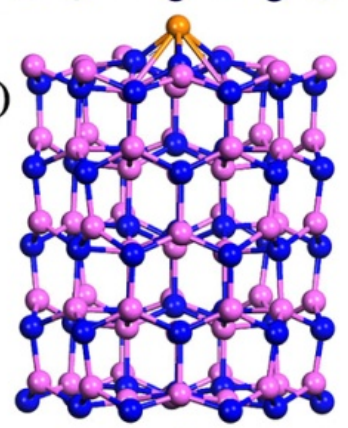

(i)

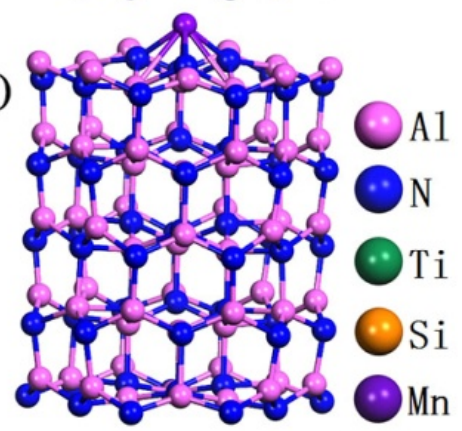

Figure 6. The optimized configurations of $\mathrm{Al}_{60} \mathrm{~N}_{60}$ cluster adsorbing $\mathrm{M}$ atom at three positions with higher adsorption energy values: Ti atom is located at the (a) edge, (b) side, (c) top position of $\mathrm{Al}_{60} \mathrm{~N}_{60}$ cluster. Si atom is located at the (d) edge, (e) side, (f) top of $\mathrm{Al}_{60} \mathrm{~N}_{60}$ cluster. Mn atom is located at the (g) edge, (h) side, (i) top of $\mathrm{Al}_{60} \mathrm{~N}_{60}$ cluster.

Figure 7 is the differential charge density diagram corresponding to the higher adsorption energy values when $\mathrm{Ti}$, Si or $\mathrm{Mn}$ atom is adsorbed on an $\mathrm{Al}_{60} \mathrm{~N}_{60}$ cluster. When three kinds of atoms are 
adsorbed at the side position of the cluster and $\mathrm{Ti}$ atom is adsorbed at the edge, a small amount of charge accumulation will appear at the No.60 and No.57 Al atoms at the far end, and charge depletion will occur at the No.12, No.19 and No.23 N atoms, and the charge distribution will be spindle-like. When a Ti, Si or Mn atom is adsorbed at the top of the cluster, the charge distribution is more uniform. There is a charge aggregation phenomenon between the three kinds of atoms and the $\mathrm{Al}_{60} \mathrm{~N}_{60}$ cluster, and the $\mathrm{Ti}, \mathrm{Si}$ and $\mathrm{Mn}$ atoms are bonded with the $\mathrm{N}$ atom at the top position of the cluster. $\mathrm{Thus,}$ when $\mathrm{Ti}$, $\mathrm{Si}$ or $\mathrm{Mn}$ atom is adsorbed at the top of the $\mathrm{Al}_{60} \mathrm{~N}_{60}$ cluster, they can have a relatively stable structure and the charge distribution is uniform. In the next section, we will select these configurations of hetero-atom modified at the top position of the $\mathrm{Al}_{60} \mathrm{~N}_{60}$ cluster to carry out their adsorption properties towards hazardous gas molecules.

(a)

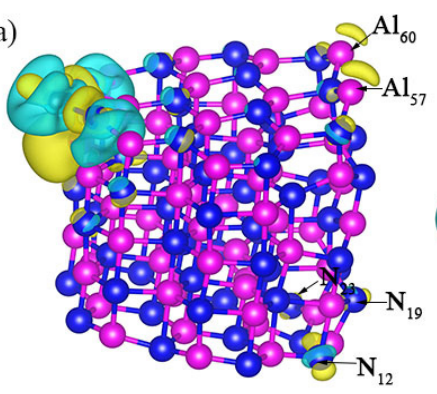

(d)

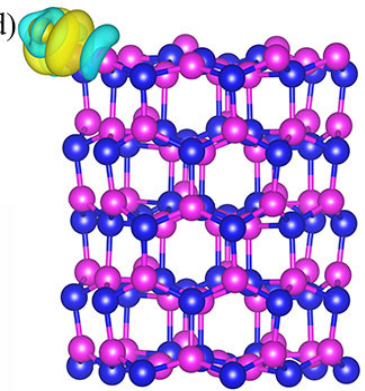

(g)

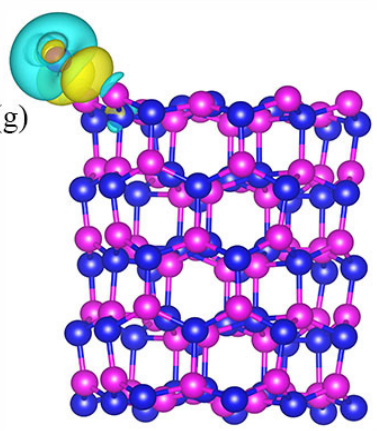

(b)
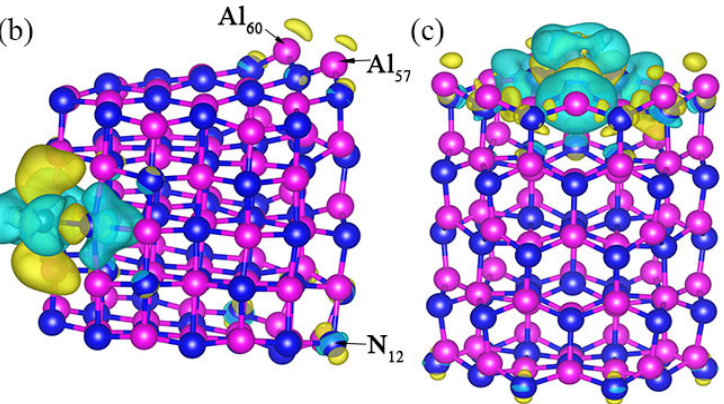

(e)
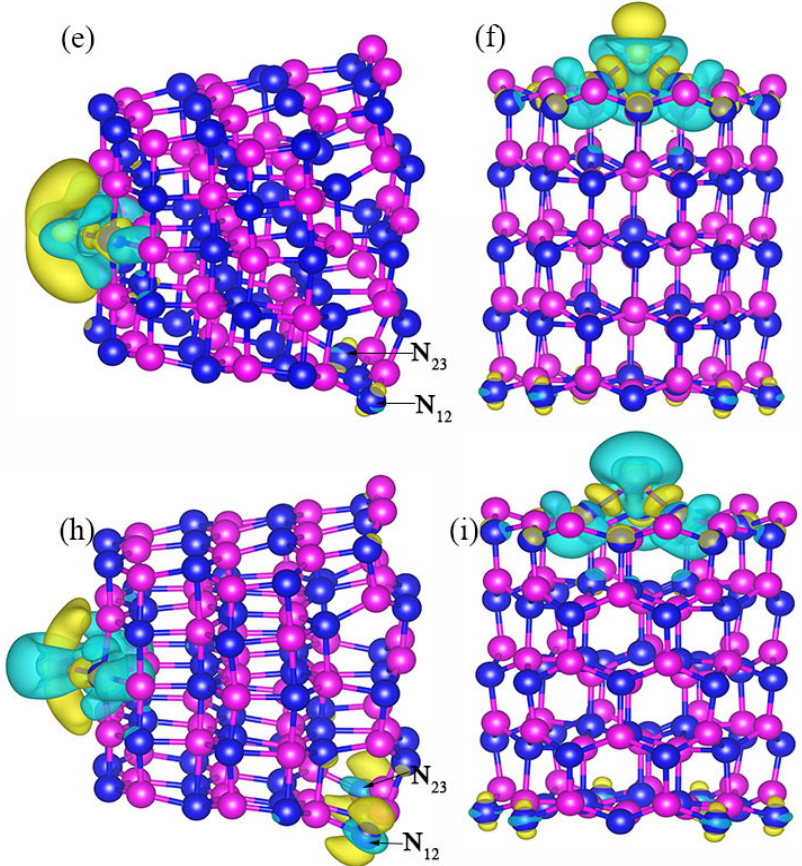

Figure 7. Differential charge density of $\mathrm{Al}_{60} \mathrm{~N}_{60}$ cluster with higher adsorption energy values for single Ti, Si or Mn atom at three positions: (a) edge, (b) side, (c) top adsorption of Ti atom. (d) edge, (e) side, (f) top adsorption of Si atom. (g) edge, (h) side, (i) top adsorption Mn atom. Yellow and blue represent the charge accumulation and depletion (isosurface $=0.0025 \mathrm{e} / \AA^{3}$ ).

\subsection{Investigation on the Adsorption of Hazardous Gas Molecules by Ti, Si or Mn-Modified $A l_{60} N_{60}$ Cluster}

$\mathrm{NO}_{2}, \mathrm{NO}, \mathrm{CO}_{2}, \mathrm{CO}$, and $\mathrm{SO}_{2}$ gas molecules are adsorbed at the stable sites of $\mathrm{Al}_{60} \mathrm{~N}_{60}$ clusters modified by $\mathrm{Ti}$, Si or $\mathrm{Mn}$ atom. After structural relaxations, the optimized configurations are shown in Figure 8. After relaxations, the heteroatom-modified $\mathrm{Al}_{60} \mathrm{~N}_{60}$ clusters are not sensitive to $\mathrm{CO}_{2}$ and do not easily adsorb $\mathrm{CO}_{2}$; the $\mathrm{Si}-\mathrm{Al}_{60} \mathrm{~N}_{60}$ cluster does not easily adsorb $\mathrm{CO}$ and $\mathrm{SO}_{2}$, which can be further proved from Table 3. The $\mathrm{M}-\mathrm{Al}_{60} \mathrm{~N}_{60}$ cluster adsorbs $\mathrm{CO}_{2}$ with a smaller adsorption energy value, which is physical adsorption. Moreover, $\mathrm{CO}_{2}$ has a longer adsorption distance from the substrate. 
Compared with the structure before adsorption, $\mathrm{CO}_{2}$ is repelled by the substrate. The adsorption energy value of $\mathrm{Si}-\mathrm{Al}_{60} \mathrm{~N}_{60}$ cluster towards $\mathrm{CO}$ or $\mathrm{SO}_{2}$ is relatively small, and the adsorption distance is relatively long, which is weak adsorption. When the $\mathrm{M}-\mathrm{Al}_{60} \mathrm{~N}_{60}$ cluster adsorbs these five gas molecules, the bond length of the gas is elongated. Except the linear $\mathrm{NO}$ and $\mathrm{CO}$, the bond angles of other molecules shrink. As can be seen from the table, the Ti-modified $\mathrm{Al}_{60} \mathrm{~N}_{60}$ cluster has higher adsorption energy values when adsorbing $\mathrm{NO}_{2}, \mathrm{NO}, \mathrm{CO}$ and $\mathrm{SO}_{2}$.

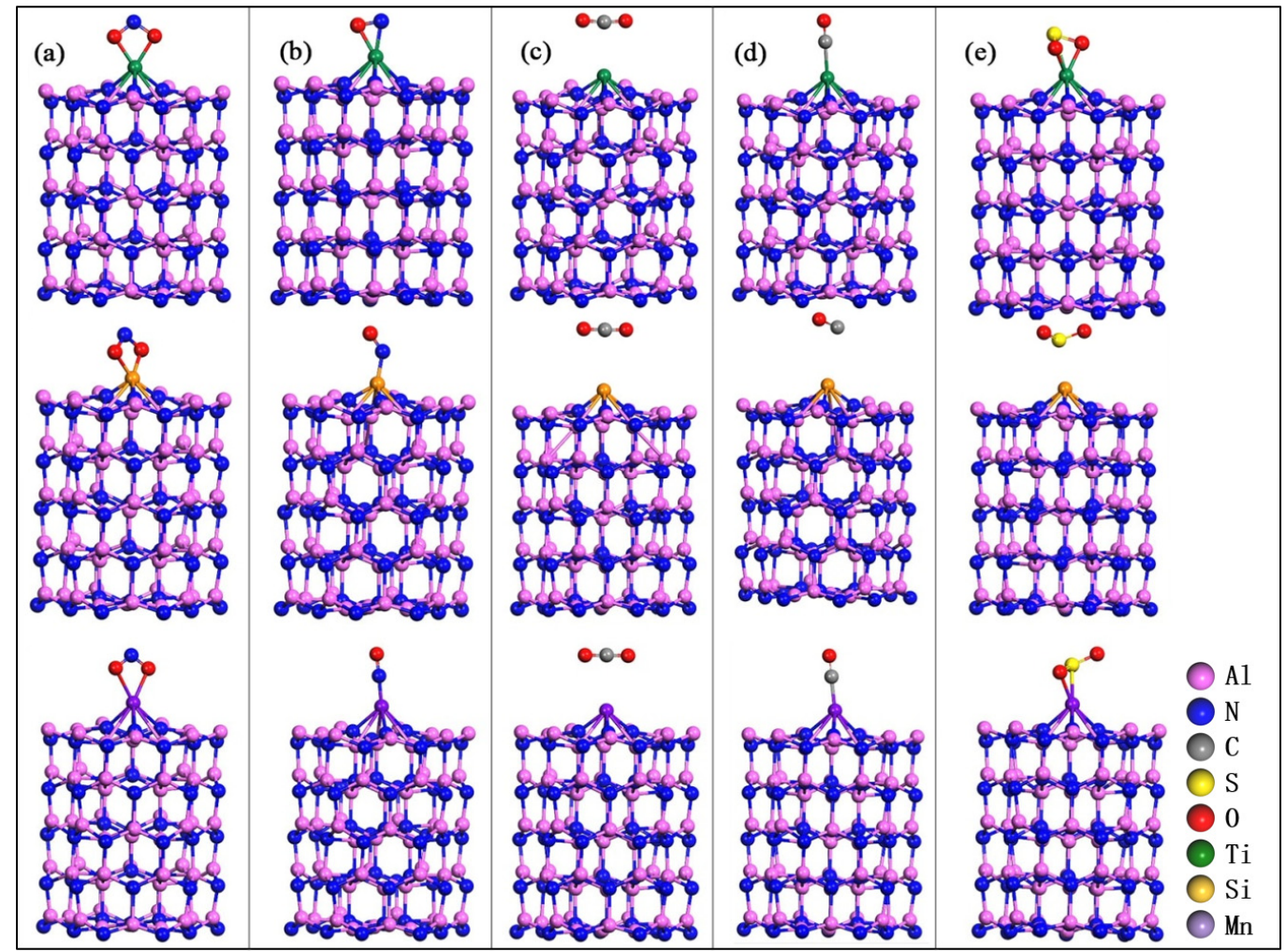

Figure 8. The optimal configurations of (a) $\mathrm{NO}_{2}$, (b) $\mathrm{NO},(\mathbf{c}) \mathrm{CO}_{2}$, (d) $\mathrm{CO}$ and (e) $\mathrm{SO}_{2}$ adsorption on $\mathrm{Al}_{60} \mathrm{~N}_{60}$ cluster modified by Ti, $\mathrm{Si}$ and $\mathrm{Mn}$ atoms. Top down: Ti, Si and Mn adsorption systems respectively.

Table 3. The adsorption energy $\left(\mathrm{E}_{\mathrm{ad}}\right)$, adsorption distance $(\mathrm{d})$, bond length $\left(\mathrm{d}_{(\mathrm{X}-\mathrm{O})}\right)$, and bond angle $(\angle(\mathrm{O}-\mathrm{X}-\mathrm{O})),(\mathrm{X}$ represents $\mathrm{N}, \mathrm{C}$ or $\mathrm{S}$ atom $)$. Adsorption distance is defined as the shortest distance from an atom of gas molecule to an atom in the modified matrix.

\begin{tabular}{|c|c|c|c|c|}
\hline Systems & $E_{a d}(e V)$ & d $(\AA)$ & $d_{(x-0)}(\AA)$ & $L_{(\mathrm{O}-\mathrm{X}-\mathrm{O})}\left(^{\circ}\right)$ \\
\hline $\mathrm{Ti}-\mathrm{Al}_{60} \mathrm{~N}_{60}+\mathrm{NO}_{2}$ & -3.99 & 1.98 & 1.35 & 105.95 \\
\hline $\mathrm{Si}-\mathrm{Al}_{60} \mathrm{~N}_{60}+\mathrm{NO}_{2}$ & -2.25 & 1.80 & 1.36 & 101.44 \\
\hline $\mathrm{Mn}-\mathrm{Al}_{60} \mathrm{~N}_{60}+\mathrm{NO}_{2}$ & -2.89 & 2.17 & 1.28 & 111.62 \\
\hline Ti- $\mathrm{Al}_{60} \mathrm{~N}_{60}+\mathrm{NO}$ & -3.37 & 1.88 & 1.37 & 180 \\
\hline $\mathrm{Si}-\mathrm{Al}_{60} \mathrm{~N}_{60}+\mathrm{NO}$ & -0.93 & 1.72 & 1.27 & 180 \\
\hline $\mathrm{Mn}-\mathrm{Al}_{60} \mathrm{~N}_{60}+\mathrm{NO}$ & -2.97 & 1.70 & 1.21 & 180 \\
\hline $\mathrm{Ti}-\mathrm{Al}_{60} \mathrm{~N}_{60}+\mathrm{CO}_{2}$ & -0.12 & 2.98 & 1.19 & 172.22 \\
\hline $\mathrm{Si}-\mathrm{Al}_{60} \mathrm{~N}_{60}+\mathrm{CO}_{2}$ & -0.15 & 3.35 & 1.18 & 177.44 \\
\hline $\mathrm{Mn}-\mathrm{Al}_{60} \mathrm{~N}_{60}+\mathrm{CO}_{2}$ & -0.08 & 3.04 & 1.18 & 178.19 \\
\hline $\mathrm{Ti}-\mathrm{Al}_{60} \mathrm{~N}_{60}+\mathrm{CO}$ & -1.74 & 2.04 & 1.18 & 180 \\
\hline $\mathrm{Si}-\mathrm{Al}_{60} \mathrm{~N}_{60}+\mathrm{CO}$ & -0.07 & 3.35 & 1.15 & 180 \\
\hline $\mathrm{Mn}-\mathrm{Al}_{60} \mathrm{~N}_{60}+\mathrm{CO}$ & -1.44 & 1.90 & 1.17 & 180 \\
\hline $\mathrm{Ti}-\mathrm{Al}_{60} \mathrm{~N}_{60}+\mathrm{SO}_{2}$ & -3.59 & 2.02 & 1.62 & 98.31 \\
\hline $\mathrm{Si}-\mathrm{Al}_{60} \mathrm{~N}_{60}+\mathrm{SO}_{2}$ & -0.43 & 2.74 & 1.47 & 116.86 \\
\hline $\mathrm{Mn}-\mathrm{Al}_{60} \mathrm{~N}_{60}+\mathrm{SO}_{2}$ & -2.06 & 1.93 & 1.54 & 113.89 \\
\hline
\end{tabular}


In order to further study the mechanism of $\mathrm{M}-\mathrm{Al}_{60} \mathrm{~N}_{60}$ clusters adsorption of those gas molecules, we have analyzed the differential charge density and charge transfer of $\mathrm{M}-\mathrm{Al}_{60} \mathrm{~N}_{60}$ clusters adsorbing $\mathrm{NO}_{2}, \mathrm{NO}, \mathrm{CO}_{2}, \mathrm{CO}$ and $\mathrm{SO}_{2}$, respectively. As can be seen from Figure 9, the charge in all systems is transferred from the modified $\mathrm{Al}_{60} \mathrm{~N}_{60}$ cluster to the gas molecule. The system of $\mathrm{M}-\mathrm{Al}_{60} \mathrm{~N}_{60}$ cluster adsorbing $\mathrm{CO}_{2}$ and $\mathrm{Si}-\mathrm{Al}_{60} \mathrm{~N}_{60}$ cluster adsorbing $\mathrm{CO}$ have smaller charge transfer and weaker interactions between gas and matrix. The system of $\mathrm{Si}-\mathrm{Al}_{60} \mathrm{~N}_{60}$ cluster adsorbing $\mathrm{CO}_{2}$ and $\mathrm{CO}$ hardly shows charge aggregation and loss. The $\mathrm{Al}_{60} \mathrm{~N}_{60}$ clusters modified with $\mathrm{Ti}$, Si or Mn atom do not easily adsorb $\mathrm{CO}_{2}$. When $\mathrm{M}-\mathrm{Al}_{60} \mathrm{~N}_{60}$ clusters adsorb $\mathrm{NO}_{2}, \mathrm{NO}$ and $\mathrm{SO}_{2}$, the charge transfers are large and there are strong interactions between gas and matrix. When Ti- $\mathrm{Al}_{60} \mathrm{~N}_{60}$ and $\mathrm{Mn}-\mathrm{Al}_{60} \mathrm{~N}_{60}$ cluster adsorb those molecules, charge aggregation occurs between the gas and the matrix. When the $\mathrm{Si}-\mathrm{Al}_{60} \mathrm{~N}_{60}$ cluster adsorbs $\mathrm{NO}_{2}$ and $\mathrm{NO}$, there is charge depletion between gas and $\mathrm{Si}_{-} \mathrm{Al}_{60} \mathrm{~N}_{60}$ cluster. When $\mathrm{M}-\mathrm{Al}_{60} \mathrm{~N}_{60}$ clusters adsorb $\mathrm{NO}_{2}$ and $\mathrm{SO}_{2}$, the $\mathrm{O}$ atoms can form bonds with the heteroatom $\mathrm{M}$. When the $\mathrm{M}-\mathrm{Al}_{60} \mathrm{~N}_{60}$ clusters adsorb $\mathrm{NO}$, the $\mathrm{N}$ atoms easily form bonds with the $\mathrm{M}$ atom and the $\mathrm{N}$ atoms gain electrons.

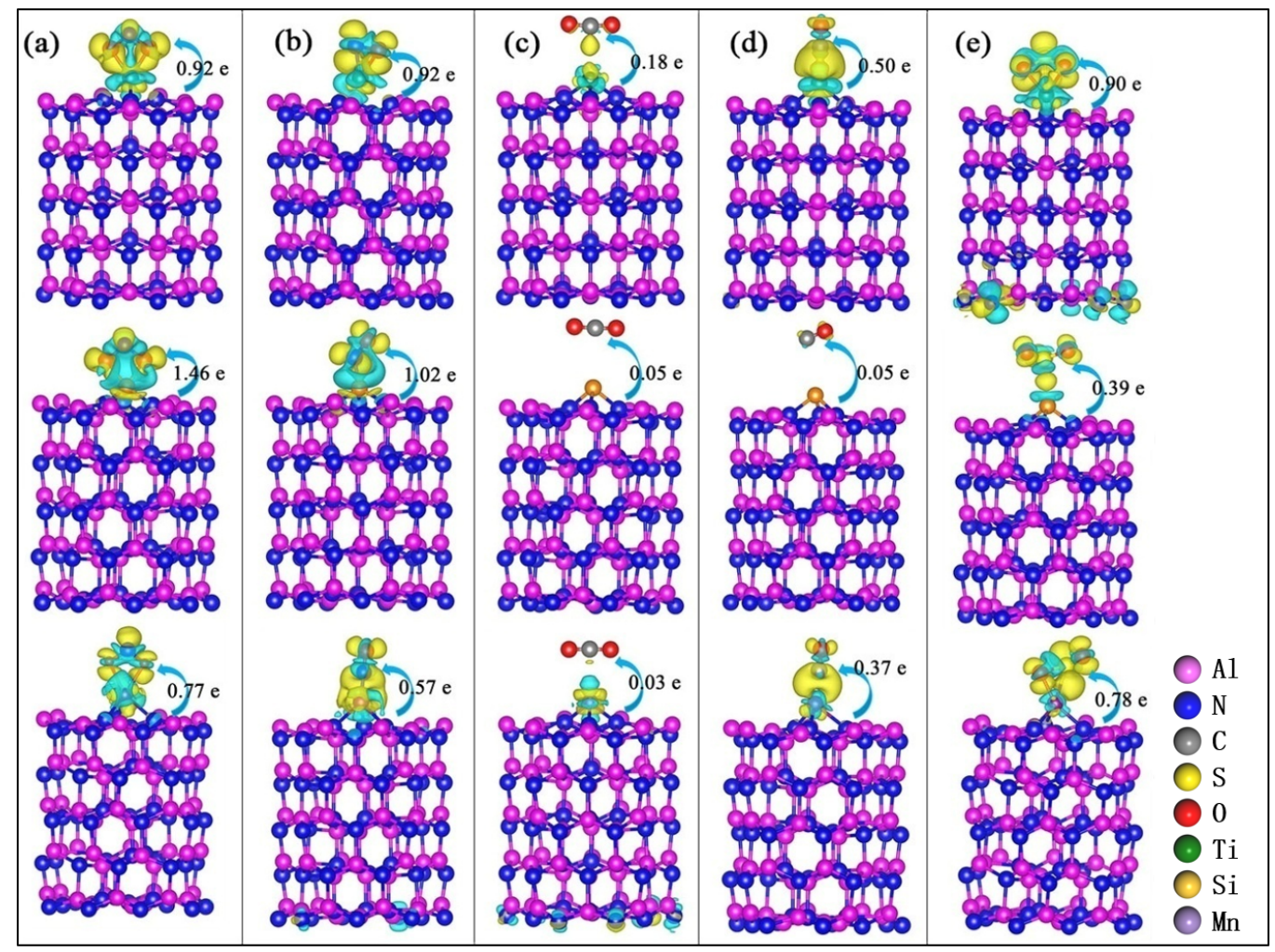

Figure 9. Differential charge density and charge transfer of (a) $\mathrm{NO}_{2},(\mathbf{b}) \mathrm{NO},(\mathbf{c}) \mathrm{CO}_{2}$, (d) $\mathrm{CO}$ and (e) $\mathrm{SO}_{2}$ adsorption on the $\mathrm{Al}_{60} \mathrm{~N}_{60}$ cluster modified by $\mathrm{Ti}$, Si or Mn atom. Top down in each subbox: Ti, Si and $\mathrm{Mn}$ adsorption systems respectively. Yellow and blue represent the charge accumulation and depletion (isosurface $=0.0025 \mathrm{e} / \AA^{3}$ ). Arrows and values represent the direction and amount of charge transfer.

To further figure out the electronic structure changes of the $\mathrm{Ti}$, Si or Mn-modified $\mathrm{Al}_{60} \mathrm{~N}_{60}$ clusters adsorbing those five hazardous gas molecules, we have calculated their corresponding density of states as shown in Figure 10. It can be seen from the figure that for the $\mathrm{M}-\mathrm{Al}_{60} \mathrm{~N}_{60}$ clusters adsorbing $\mathrm{NO}_{2}$, $\mathrm{NO}, \mathrm{CO}_{2}, \mathrm{CO}$ and $\mathrm{SO}_{2}$, the energy gap of the system varies and the effects of three modifying atoms on the electronic structures are also different. In the figure, $\Delta \mathrm{E}_{\mathrm{g}}$ represents the energy gap change of the system before and after hetero-atom modification and the formula is as follows:

$$
\Delta E_{g}=E_{g}\left(M-\mathrm{Al}_{60} \mathrm{~N}_{60}+\text { gas }\right)-\mathrm{E}_{\mathrm{g}\left(\mathrm{Al}_{60} \mathrm{~N}_{60}+\text { gas }\right)}
$$


where $\mathrm{E}_{\mathrm{g}\left(\mathrm{M}-\mathrm{Al}_{60} \mathrm{~N}_{60}+\text { gas }\right)}$ represents the energy gap of the gas adsorption system by modified $\mathrm{Al}_{60} \mathrm{~N}_{60}$ cluster with $\mathrm{M}$ heteroatoms, $\mathrm{E}_{\mathrm{g}\left(\mathrm{Al}_{60} \mathrm{~N}_{60}+\text { gas }\right)}$ represents the gap of the system by pure $\mathrm{Al}_{60} \mathrm{~N}_{60}$ cluster. It is found that for the Ti- $\mathrm{Al}_{60} \mathrm{~N}_{60}$ cluster adsorbing $\mathrm{CO}_{2}, \mathrm{CO}$, and $\mathrm{SO}_{2}$ and the $\mathrm{Mn}-\mathrm{Al}_{60} \mathrm{~N}_{60}$ cluster adsorbing $\mathrm{CO}_{2}$, the energy gap of these four systems are sharply reduced and the energy gap change rate are $75 \%, 62 \%, 50 \%$ and $57 \%$ respectively. The change rate of energy gap of $\mathrm{Ti}^{-} \mathrm{Al}_{60} \mathrm{~N}_{60}$ cluster adsorbing $\mathrm{NO}_{2}$ was $25 \%$. While, the energy gap of Si-modified $\mathrm{Al}_{60} \mathrm{~N}_{60}$ cluster after adsorbing $\mathrm{NO}$ is unchanged. The energy gaps of the Ti- $\mathrm{Al}_{60} \mathrm{~N}_{60}$ cluster adsorbing $\mathrm{CO}_{2}, \mathrm{CO}$ and $\mathrm{SO}_{2}$ and the $\mathrm{Mn}-\mathrm{Al}_{60} \mathrm{~N}_{60}$ cluster adsorbing $\mathrm{CO}_{2}$ are decreased, but the $\mathrm{Al}_{60} \mathrm{~N}_{60}$ clusters modified by Ti or $\mathrm{Mn}$ atom do not easily adsorb $\mathrm{CO}_{2}$. Therefore, it is regarded that the Ti-atom modification can improve the sensitivity and sensing of $\mathrm{Al}_{60} \mathrm{~N}_{60}$ cluster towards $\mathrm{CO}$ and $\mathrm{SO}_{2}$ and have potential to be used as a choice of related gas-sensing materials design.
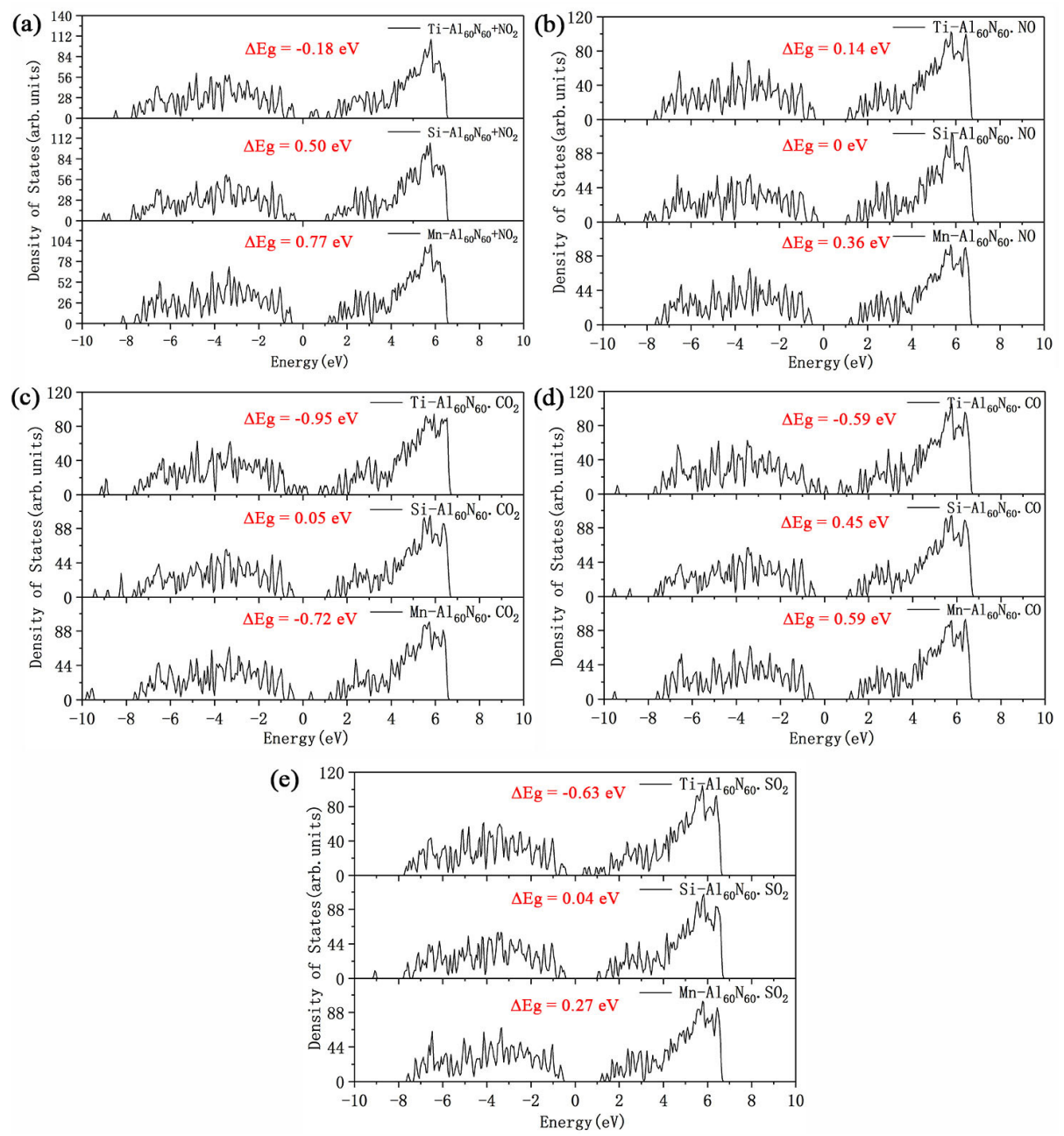

Figure 10. Density of states of various $\mathrm{M}-\mathrm{Al}_{60} \mathrm{~N}_{60}$ clusters adsorbing five gas molecules respectively: (a) $\mathrm{NO}_{2} ;$ (b) $\mathrm{NO}$; (c) $\mathrm{CO}_{2} ;$ (d) $\mathrm{CO} ;(\mathbf{e}) \mathrm{SO}_{2}$. The Fermi level is set at zero. $\Delta$ Eg represents the energy gap change of the system before and after hetero-atom $(\mathrm{M})$ modification.

\section{Summary and Outlook}

We have systematically investigated the atomic scale configurations and electronic structures of various hazardous gas molecules adsorbed by pure and heteroatom-modified $\mathrm{Al}_{60} \mathrm{~N}_{60}$ clusters with Ti, $\mathrm{Si}$ and Mn using Density Functional Theory. It is found that for the pure $\mathrm{Al}_{60} \mathrm{~N}_{60}$ cluster adsorbing those gas molecules, when $\mathrm{NO}_{2}, \mathrm{NO}, \mathrm{CO}_{2}, \mathrm{CO}$ and $\mathrm{SO}_{2}$ are adsorbed on the top.b, edge. $\mathrm{a}_{\mathrm{p}}$, edge. $\mathrm{a}_{\mathrm{h}}$, edge. $\mathrm{a}_{\mathrm{p}}$ and edge. $a_{h}$ sites of the nanocluster, respectively, the corresponding structures are relatively stable and the charge transfer is relatively large. The chemisorption between $\mathrm{Al}_{60} \mathrm{~N}_{60}$ cluster and gas molecule in 
these five systems is strong. The energy gap of pure $\mathrm{Al}_{60} \mathrm{~N}_{60}$ cluster is reduced by $44 \%$ when adsorbing $\mathrm{NO}_{2}$ at its stable site, which is expected to be a candidate gas sensing material for $\mathrm{NO}_{2}$. When $\mathrm{Ti}$, $\mathrm{Si}$ and $\mathrm{Mn}$ atoms are respectively adsorbed on the top sites of $\mathrm{Al}_{60} \mathrm{~N}_{60}$ cluster, the corresponding structures are relatively stable and the charge distribution is uniform. When Ti-modified $\mathrm{Al}_{60} \mathrm{~N}_{60}$ cluster adsorbs $\mathrm{CO}$ and $\mathrm{SO}_{2}$ gas molecules, the energy gap decreases sharply. Compared with the pure cluster adsorption system, the energy gap changes by $62 \%$ and $50 \%$ respectively, which greatly improves the sensitivity of $\mathrm{Al}_{60} \mathrm{~N}_{60}$ nanocluster to $\mathrm{CO}$ and $\mathrm{SO}_{2}$. This theoretical work is proposed to supply fundamental clues and guide for experimentalists to develop appropriate nanoclusters for environmental and health applications.

Author Contributions: Formal analysis, X.N., Z.Q.; Project administration, Z.Q., W.D., P.Z., L.W., R.A. and J.P.; Supervision, Z.Q.; Writing-original draft, X.N., Q.L. and Z.Q. All authors have read and agreed to the published version of the manuscript.

Funding: We thank the support from the Natural Science Foundation of China (51801113), the Natural Science Foundation of Shandong Province (ZR2018MEM001), the Young Scholars Program of Shandong University (YSPSDU) and the Education Program of Shandong University (2020Y299).

Acknowledgments: The National Supercomputer Centre (NSC) and the HPC Cloud Platform of Shandong University are acknowledged. R.A. thanks to SNIC \& HPC2N, Sweden for providing the computing facilities.

Conflicts of Interest: The authors declare no conflict of interest.

\section{References}

1. Soltani, A.; Peyghan, A.A.; Bagheri, Z. $\mathrm{H}_{2} \mathrm{O}_{2}$ Adsorption on the BN and $\mathrm{SiC}$ Nanotubes: A DFT Study. Phys. E Low-Dimens. Syst. Nanostruct. 2013, 48, 176-180. [CrossRef]

2. Salih, E.; Mekawy, M.; Hassan, R.Y.A.; El-Sherbiny, I.M. Synthesis, Characterization and Electrochemical-sensor Applications of Zinc Oxide/graphene Oxide Nanocomposite. J. Nanostruct. Chem. 2016, 6, 137-144. [CrossRef]

3. Beheshtian, J.; Peyghan, A.A.; Bagheri, Z.; Kamfiroozi, M. Interaction of Small Molecules $\left(\mathrm{NO}_{2} \mathrm{H}_{2}, \mathrm{~N}_{2}\right.$, and $\mathrm{CH}_{4}$ ) with BN Nanocluster Surface. Struct. Chem. 2012, 23, 1567-1572. [CrossRef]

4. Ruiz, E.; Alvarez, S.; Alemany, P. Electronic Structure and Properties of AlN. Phys. Rev. B 1994, 49, 7115-7123. [CrossRef] [PubMed]

5. Tang, Y.B.; Liu, Y.Q.; Sun, C.H.; Cong, H.T. AlN Nanowires for Al-based Composites with High Strength and Low Thermal Expansion. J. Mater. Res. 2007, 22, 2711-2718. [CrossRef]

6. Rubio, A.; Corkill, J.L.; Cohen, M.L.; Shirley, E.L.; Louie, S.G. Quasi particle Band Structureof AlN and GaN. Phys. Rev. B 1993, 48, 11810-11816. [CrossRef]

7. Taylor, K.M.; Lenie, C. Some Properties of Aluminum Nitride. J. Electrochem. Soc. 1960, 107, 308-314. [CrossRef]

8. Ouyang, T.; Qian, Z.; Hao, X.; Ahuja, R.; Liu, X. Effect of Defects on Adsorption Characteristics of AlN Monolayer towards $\mathrm{SO}_{2}$ and $\mathrm{NO}_{2}$ : Ab initio Exposure. Appl. Surf. Sci. 2018, 462, 615-622. [CrossRef]

9. Samadizadeh, M.; Rastegar, S.F.; Peyghan, A.A. $\mathrm{F}^{-}, \mathrm{Cl}^{-}, \mathrm{Li}^{+}$and $\mathrm{Na}^{+}$Adsorption on AlN Nanotube Surface: A DFT Study. Phys. E Low-Dimens. Syst. Nanostruct. 2015, 69, 75-80. [CrossRef]

10. Wang, Y.; Song, N.; Song, X.; Zhang, T.; Yang, D. A First-principles Study of Gas Adsorption on Monolayer AlN Sheet. Vacuum 2018, 147, 18-23. [CrossRef]

11. Ouyang, T.; Qian, Z.; Ahuja, R.; Liu, X. First-principles Investigation of CO Adsorption on Pristine, C-doped and N-vacancy Defected Hexagonal AlN Nanosheets. Appl. Surf. Sci. 2018, 439, 196-201. [CrossRef]

12. Beheshtian, J.; Baei, M.T.; Peyghan, A.A.; Bagheri, Z. Nitrous Oxide Adsorption on Pristine and Si-doped AlN Nanotubes. J. Mol. Modeling 2013, 19, 943-949. [CrossRef] [PubMed]

13. Rastegar, S.F.; Peyghan, A.A.; Hadipour, N.L. Response of Si- and Al-doped Graphenes toward HCN: A Computational Study. Appl. Surf. Sci. 2013, 265, 412-417. [CrossRef]

14. Hadipour, N.L.; Peyghan, A.A.; Soleymanabadi, H. Theoretical Study on the Al-doped ZnO Nanoclusters for CO Chemical Sensors. J. Phys. Chem. C 2015, 119, 6398-6404. [CrossRef]

15. Aslanzadeh, S. Transition Metal Doped ZnO Nanoclusters for Carbon Monoxide Detection: DFT Studies. J. Mol. Modeling 2016, 22, 160. [CrossRef] 
16. Sameti, M.R.; Jamil, E.S. The Adsorption of CO Molecule on Pristine, As, B, BAs Doped $(4,4)$ Armchair AlNNTs: A Computational Study. J. Nanostruct. Chem. 2016, 6, 197-205. [CrossRef]

17. Saedi, L.; Javanshir, Z.; Khanahmadzadeh, S.; Maskanati, M.; Nouraliei, M. Determination of $\mathrm{H}_{2} \mathrm{~S}, \mathrm{COS}_{2} \mathrm{CS}_{2}$ and $\mathrm{SO}_{2}$ by An Aluminium Nitride Nanocluster: DFT Studies. Mol. Phys. 2020, 7, 118. [CrossRef]

18. Nie, X.; Qian, Z.; Du, W.; Lu, Z.; Li, H.; Ahuja, R.; Liu, X. Structural Evolution of AlN Nanoclusters and the Elemental Chemisorption Characteristics: Atomistic Insight. Nanomaterials 2019, 9, 1420. [CrossRef]

19. Kohn, W.; Sham, L.J. Self-Consistent Equations Including Exchange and Correlation Effects. Phys. Rev. 1965, 140, A1133-A1138. [CrossRef]

20. Hohenberg, P.; Kohn, W. Inhomogeneous Electron Gas. Phys. Rev. 1964, 136, B864-B871. [CrossRef]

21. Kresse, G.; Joubert, D. From Ultrasoft Pseudopotentials to the Projector Augmented Wave Method. Phys. Rev. B 1999, 59, 1758-1775. [CrossRef]

22. Kresse, G.; Furthmüller, J. Efficiency of Ab-Initio Total Energy Calculations for Metalsand Semiconductors Using A Plane-Wave Basis Set. Comput. Mater. Sci. 1996, 6, 15-50. [CrossRef]

23. Kresse, G.; Furthmüller, J. Efficient Iterative Schemes for ab Initio Total-Energy Calculations Using A Plane-Wave Basis Set. Phys. Rev. B 1996, 54, 169-186. [CrossRef]

24. Perdew, J.P.; Burke, K.; Ernzerhof, M. Generalized Gradient Approximation Made Simple. Phys. Rev. Lett. 1996, 77, 3865-3868. [CrossRef]

25. Grimme, S. Semiempirical GGA-type Density Functional Constructed with A Longrange Dispersion Correction. J. Comput. Chem. 2006, 27, 1787-1799. [CrossRef]

26. Cioslowski, J. Atoms in Molecules-a Quantum Theory-bader, RFW. Science 1991, 252, 1566-1567. [CrossRef]

27. Tang, W.; Sanville, E.; Henkelman, G. A Grid-based Bader Analysis Algorithm without Lattice Bias. J. Phys. Condens. Matter 2009, 21, 084204. [CrossRef]

28. Nie, X.; Qian, Z.; Li, H.; Ahuja, R.; Liu, X. Theoretical Prediction of A Novel Aluminum Nitride Nanostructure: Atomistic Exposure. Ceram. Int. 2019, 45, 23690-23693. [CrossRef]

Publisher's Note: MDPI stays neutral with regard to jurisdictional claims in published maps and institutional affiliations.

(C) 2020 by the authors. Licensee MDPI, Basel, Switzerland. This article is an open access article distributed under the terms and conditions of the Creative Commons Attribution (CC BY) license (http://creativecommons.org/licenses/by/4.0/). 